\title{
Shopping for Health: Foods with Added Fiber ${ }^{1}$
}

\author{
Wendy J. Dahl ${ }^{2}$
}

Fiber in foods consists of carbohydrates that cannot be digested. Although many foods naturally contain fiber, high-fiber ingredients are commonly added to foods to increase their fiber content. Fiber ingredients may be added to foods for health or functional reasons.

Fibers, such as carrageenan, guar gum, xanthan gum, and pectin, are added to foods to thicken or stabilize them. For example, carrageenan, which is found in chocolate milk, and xanthan gum, which is found in salad dressings, are both added to prevent ingredients from settling at the bottom of the container. Pectin is added to jams and jellies to thicken them. In addition, some fiber ingredients, when dispersed in water, have a fat-like texture that can be used to replace a portion of fat in some foods. Adding fiber to foods also increases water absorption, preserves moisture, affects crumb texture and tenderness, and modifies color and flavor. As only very small amounts of these fibers are used in most foods, they contribute little to total fiber intake.

\section{Can Foods With Added Fiber Help Increase Fiber Intake?}

In terms of nutrition, increasing the total fiber content of foods is the most important reason for adding fiber to foods. Although fiber is naturally present in fruits, vegetables, whole grains, beans, nuts, and seeds, most people do not consume enough of these foods. Thus, they consume far less fiber than recommended (USDA, 2003-2006). In attempts to help people reach their recommended fiber intake, fiber ingredients are currently being added to breakfast cereals, breads, snack bars, yogurts, and beverages.

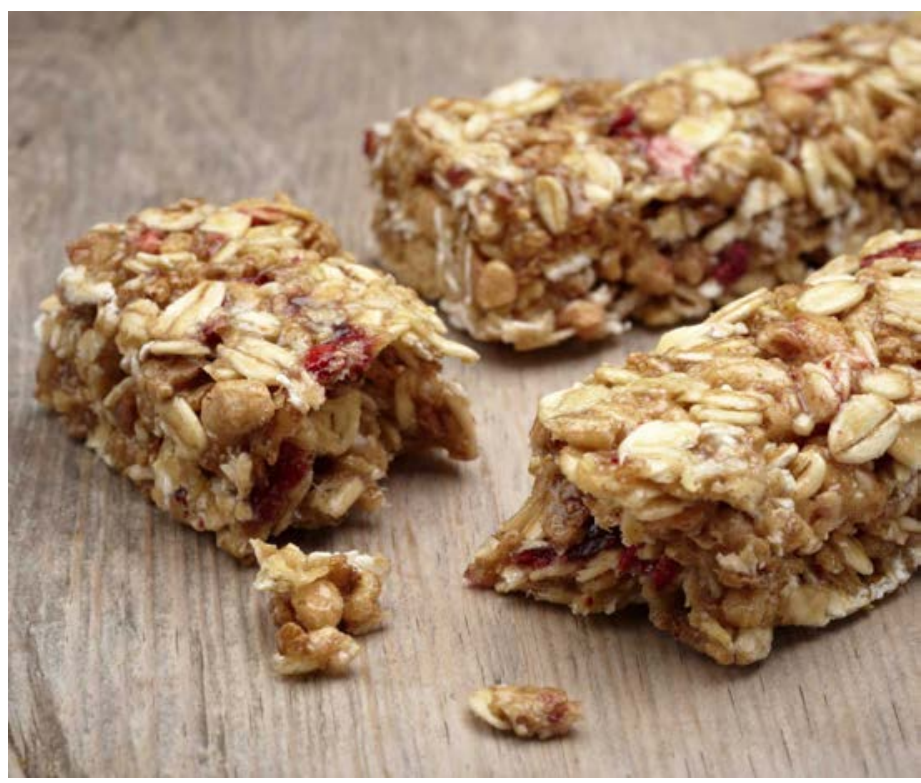

Credits: iStock

Many different fiber ingredients are added to foods to increase their fiber content. Some examples of added fiber ingredients are wheat bran, soy fiber, chicory root fiber, cellulose, corn bran, and pea hull fiber. These fibers have been isolated from various grain, legume, or vegetable crops. For example, chicory root fiber or inulin, is isolated from the root of the chicory plant, in a process similar to how sugar beets are processed into table sugar. Other fibers, such as corn bran or pea hull, are made by removing and grinding the bran or hull from the cereal or legume seed. Further

1. This document is FSHN13-11, one of a series of the Food Science and Human Nutrition Department, UF/IFAS Extension. Original publication date November 2013. Visit the EDIS website at http://edis.ifas.ufl.edu.

2. Wendy J. Dahl, assistant professor, Food Science and Human Nutrition Department, UF/IFAS Extension, Gainesville, FL 32611.

The Institute of Food and Agricultural Sciences (IFAS) is an Equal Opportunity Institution authorized to provide research, educational information and other services only to individuals and institutions that function with non-discrimination with respect to race, creed, color, religion, age, disability, sex, sexual orientation, marital status, national origin, political opinions or affiliations. For more information on obtaining other UF/IFAS Extension publications, contact your county's UF/IFAS Extension office. 
processing, such as washing and bleaching, can improve the taste and lessen the color of the fiber ingredient.

\section{How Much Fiber Is Added To Foods?}

The amount of fiber added to foods varies. When at least $2.5 \mathrm{~g}$ of fiber has been added to a serving of food (compared to the original food), it can be labelled as having "more or added fiber (FDA, 2013)." A "good source of fiber" contains $2.5 \mathrm{~g}$ to $4.9 \mathrm{~g}$ of fiber per serving, and a "high fiber" food contains $5 \mathrm{~g}$ of fiber or more per serving (FDA, 2013). The total fiber content listed on the label (in g) includes both naturally-occurring dietary fiber and added fiber.

\begin{tabular}{|c|c|c|}
\hline \multirow{2}{*}{\multicolumn{3}{|c|}{$\begin{array}{l}\text { Nutrition Facts } \\
\text { Serving Size } 25 \text { Biscuits }(55 \mathrm{~g}) \\
\text { Servings Per Container About } 8\end{array}$}} \\
\hline & & \\
\hline \multicolumn{3}{|c|}{$\begin{array}{lcc}\text { Amount Per Serving } \quad \text { Cereal } & \begin{array}{c}\text { with } 1 / 2 \text { cup } \\
\text { skim milk }\end{array} \\
\end{array}$} \\
\hline Calories & 190 & 230 \\
\hline \multirow{2}{*}{ Calories from Fat } & 5 & 5 \\
\hline & \multicolumn{2}{|c|}{ \% Daily Value** } \\
\hline \multicolumn{3}{|l|}{ Total Fat $1 \mathrm{~g}^{\star}$} \\
\hline Saturated Fat $0 \mathrm{~g}$ & $\mathbf{0} \%$ & $\mathbf{0} \%$ \\
\hline \multicolumn{3}{|c|}{ Trans Fat $0 \mathrm{~g}$} \\
\hline \multicolumn{3}{|c|}{ Polyunsaturated Fat $0.5 \mathrm{~g}$} \\
\hline \multicolumn{3}{|c|}{ Monounsaturated Fat $0 \mathrm{~g}$} \\
\hline Cholesterol 0mg & O \% & $\mathbf{0} \%$ \\
\hline Sodium $0 \mathrm{mg}$ & $0 \%$ & $3 \%$ \\
\hline Potassium 190mg & $\mathbf{5} \%$ & $11 \%$ \\
\hline \multicolumn{3}{|c|}{ Total Carbohydrate $47 \mathrm{~g} \mathbf{1 6} \%$} \\
\hline Dietary Fiber 6a & $23 \%$ & $23 \%$ \\
\hline \multirow{2}{*}{\multicolumn{3}{|c|}{$\begin{array}{l}\text { Soluble Fiber less than } 1 \mathrm{~g} \\
\text { Insoluble Fiber } 5 \mathrm{~g}\end{array}$}} \\
\hline & & \\
\hline \multicolumn{3}{|c|}{ Sugars $12 \mathrm{~g}$} \\
\hline \multicolumn{3}{|c|}{ Protein $5 g$} \\
\hline \multicolumn{3}{|c|}{$\begin{array}{l}\text { Ingredients: Whole grain wheat, sugar, } \\
\text { brown sugar (sugar, molasses), } \\
\text { contains } 2 \% \text { or less of brown rice syrup, } \\
\text { natural and artificial flavor, caramel } \\
\text { color, gelatin. BHT for freshness. }\end{array}$} \\
\hline
\end{tabular}

Figure 2. Nutrition facts and ingredient list of a high-fiber, whole grain breakfast cereal.

Credits: Wendy J. Dahl

\section{What Are The Health Effects Of Added Fiber?}

Although recommendations state that healthy women should consume about $25 \mathrm{~g}$ of fiber per day and men consume $38 \mathrm{~g}$ of fiber per day (Institute of Medicine, 2005), most people do not consume enough. For maximum health benefits, choose foods that naturally contain dietary fiber, such as fruits, vegetables, beans, whole grains, nuts, and seeds. However, foods with added fiber ingredients may be considered healthy choices as well.

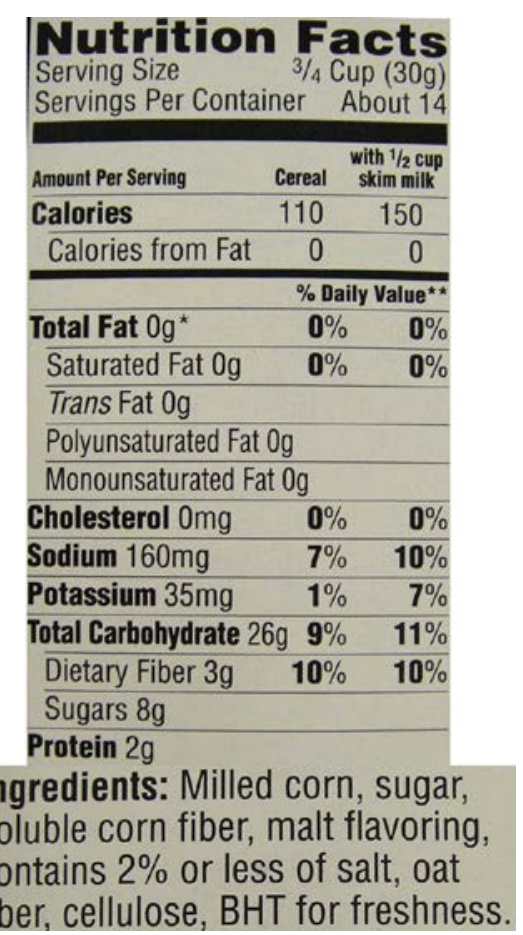

Figure 3. Nutrition facts and ingredient list of a breakfast cereal that is a good source of fiber because of added fiber. Credits: Wendy J. Dahl

Added fiber ingredients differ in their physical properties and health effects. Commonly used categories include soluble and insoluble fibers. Soluble fibers dissolve in water and are easily added to foods, often without unwanted changes in taste and texture. These fibers are often added to beverages and foods high in water, such as yogurt. Examples of soluble fiber ingredients are chicory root fiber (also called inulin or oligofructose), corn and wheat dextrins, hydrolyzed guar gum, and soy fiber. Soluble fibers, like all fibers, are not digested, but are broken down (fermented) by bacteria in the colon. Some soluble fibers, such as inulin, promote the growth of Bifidobacteria, which are thought to enhance health (Niness, 1999). The products of soluble fiber fermentation help keep our colons healthy and provide us with energy.

Some soluble fiber ingredients are viscous. When viscous fibers are eaten, the contents of the stomach thickens, which delays stomach emptying. Viscous fibers help to decrease blood glucose and cholesterol levels (Chutkan, Fahey, Wright, \& McRorie, 2012). Oatmeal and okra are two examples of foods that naturally contain viscous fibers. Since these fibers change a food's texture, viscous fibers are rarely added to food. A cookie with added viscous fiber, for example, may become "gummy" or "sticky" when chewed. An example of a viscous fiber ingredient that is added to a few foods is psyllium fiber. 
Many fiber ingredients are insoluble (do not dissolve in water), making them a rare addition to beverages. These are the best fiber choices for bulking stools and preventing constipation. Insoluble fibers work well as ingredients in baked goods, such as bread, cookies, and muffins. Many of these fibers are easily substituted for some flour in recipes, which may create a similar but healthier product because of its higher fiber and lower calorie content. Examples of insoluble fibers that are added to foods include cellulose, pea hull fiber, wheat bran, and corn bran.

When choosing foods with added fiber, consider what health outcomes you want. If prevention of constipation is needed, choose a food with added cellulose, hull, or bran fibers. If you need to reduce your blood glucose and cholesterol levels, then choose foods high in viscous fibers, such as psyllium fiber. A combination of soluble and insoluble fibers may be best for gastrointestinal wellness.

\section{References}

Chutkan, R., Fahey, G., Wright, W.L., and McRorie, J.

"Viscous versus nonviscous soluble fiber supplements: mechanisms and evidence for fiber-specific health benefits." Journal of the American Academy of Nurse Practitioners (JAANP) 24 (2012): 476-87.

U.S. Food and Drug Administration. Part 101 Food Labeling: Food and Drugs: Subchapter B. Food for Human Consumption, 2013. Retrieved from http://www. accessdata.fda.gov/scripts/cdrh/cfdocs/cfcfr/CFRSearch. cfm?CFRPart $=101$

Institute of Medicine, Food and Nutrition Board. Dietary Reference Intakes for energy, carbohydrate, fiber, fat, fatty acids, cholesterol, protein, and amino acids (pp. 339-421). Washington, DC: The National Academies Press, 2005.

Niness, K.R. "Inulin and Oligofructose: What are They?" Journal of Nutrition 129 (1999): 1402S-6S.

U.S. Department of Agriculture, Agricultural Research Service, Beltsville Human Nutrition Research Center, Food Surveys Research Group and U.S. Department of Health and Human Services, Centers for Disease Control and Prevention, National Center for Health Statistics. What We Eat in America, NHANES, 2003-2006. 